\title{
Study of the Dielectric Behaviour of Cr-Doped Zinc Nano Ferrites Synthesized by Sol-Gel Method
}

\author{
Mamilla Lakshmi', Katrapally Vijaya Kumar ${ }^{2 *}$, Krishnan Thyagarajan ${ }^{3}$ \\ ${ }^{1}$ Marri Laxman Reddy Institute of Technology \& Management, Hyderabad, India \\ ${ }^{2}$ Department of Physics, Jawaharlal Nehru Technological University Hyderabad College of Engineering Jagtial, \\ Karimnagar, India \\ ${ }^{3}$ Department of Physics, Jawaharlal Nehru Technological University Anantapur College of Engineering, \\ Pulivendula, India \\ Email: "kvkphd@gmail.com
}

Received 11 May 2016; accepted 14 June 2016; published 17 June 2016

Copyright (C) 2016 by authors and Scientific Research Publishing Inc.

This work is licensed under the Creative Commons Attribution International License (CC BY). http://creativecommons.org/licenses/by/4.0/

(c) () Open Access

\section{Abstract}

The series of $\mathrm{Cr}-\mathrm{Zn}$ nano ferrites having the general composition $\mathrm{Cr}_{x} \mathrm{ZnFe}_{2-x} \mathrm{O}_{4}(0 \leq x \leq 0.5)$ have been synthesized successfully in the nanocrystalline form using the sol-gel method. The samples were sintered at $900^{\circ} \mathrm{C}$ for 3 hours. The effect of chromium substitution on dielectric properties of $\mathrm{Zn}$-ferrites is reported in this paper. The analysis of XRD patterns revealed the formation of single phase cubic spinel structure for all the $\mathrm{Cr}$-Zn ferrite samples. The FTIR spectra show two strong absorption bands in the range of $400-600 \mathrm{~cm}^{-1}$, which corroborate the spinel structure of the samples. The average grain size was found to be in the nanometer range and of the order of 43 - 63 nm obtained using TEM images. The lattice parameter and crystallite size decrease with increase in $C r$ concentration $(x)$. The investigation on dielectric constant $(\varepsilon)$, dissipation factor $(D)$ and ac conductivity $\left(\sigma_{a c}\right)$ was carried out at a fixed frequency $1 \mathrm{kHz}$ and in the frequency range of $100 \mathrm{~Hz}$ to $1 \mathrm{MHz}$ at room temperature using LCR meter. The plots of dielectric constant $(\varepsilon)$ versus frequency show the normal dielectric behavior of spinel ferrites. The value of ac conductivity $\left(\sigma_{a c}\right)$ increases with increase in frequency for all the compositions. The appearance of the peak for each composition in the dissipation factor versus frequency curve suggests the presence of relaxing dipoles in the Cr-Zn nano ferrite samples. It is also found that the shifting of the relaxation peak towards lower frequency side with an increase in chromium content $(x)$ is due to the strengthening of dipole-dipole interactions. The composition and frequency dependence of the dielectric constant, dielectric loss and ac-conductivity are explained based on the Koop's two-layer model, Maxwell-Wagner polarization process, and Debye relaxation theory.

${ }^{*}$ Corresponding author.

How to cite this paper: Lakshmi, M., Vijaya Kumar, K. and Thyagarajan, K. (2016) Study of the Dielectric Behaviour of Cr-Doped Zinc Nano Ferrites Synthesized by Sol-Gel Method. Advances in Materials Physics and Chemistry, 6, $141-148$.

http://dx.doi.org/10.4236/ampc.2016.66015 
Keywords

\author{
Cr-Zn Nano Ferrites, Dielectric Constant, Dissipation Factor, AC Conductivity, Dipole-Dipole \\ Interaction
}

\title{
1. Introduction
}

Ferrites have paramount advantages over other types of magnetic materials due to high electrical resistivity and low eddy current losses [1] [2]. For the most favorable combination of low cost, high stability, high quality and lowest volume, ferrites are considered to be the best core material choice over a wide range of frequency [3]. Among all magnetic materials, ferrites are the most useful because in addition to magnetic properties, they are also good electrical insulators. The dielectric properties of ferrites are dependent on several factors, such as the method of preparation, heat treatment, sintering conditions, chemical composition, cation distribution, $\mathrm{pH}$, nature and type of substituent, the ratio of $\mathrm{Fe}^{3+} / \mathrm{Fe}^{2+}$ ions, frequency and crystallite size [4]-[6]. The important parameters for any dielectric substance are its dielectric constant or dielectric permittivity $\left(\varepsilon^{\prime}\right)$, which is the ability to store charge in a capacitor and dissipation factor $(D)$ which is a measure of the energy dissipation in the material. Extrinsic losses are associated with the crystal defects, e.g. porosity, grain boundaries, micro-cracks, random crystal orientations, and impurities, etc. It is evident from the previous studies [7] that the losses in sintered polycrystalline ceramics are greatly affected by these extrinsic factors. All these parameters can play a key role in the modification of the dielectric behavior of spinel ferrites which can be more useful for the desired applications.

$\mathrm{ZnFe}_{2} \mathrm{O}_{4}$ has the normal spinel structure [8] in which $\mathrm{Zn}^{2+}$ ions occupy the tetrahedral sites, and all the $\mathrm{Fe}^{3+}$ ions occupy octahedral sites. $\mathrm{ZnFe}_{2} \mathrm{O}_{4}$ exhibit good dielectric and magnetic properties; hence these ferrites have a great importance from the application point of view, where these are widely used in many ferrite devices and production of electronic and magnetic components, converters, and electromagnetic wave absorbers [9].

Polycrystalline ferrites are very good dielectric materials which have numerous applications at microwave frequencies. The study of dielectric properties gives valuable information about the behavior of localized electric charge carriers and can explain the phenomenon of dielectric polarization and electrical conduction in the material. The experimental conditions used in the preparation of these materials show a strong impact on the properties of the resultant ferrite nanoparticles. For this reason, several methods have been used in the preparation of nanoparticles, like the co-precipitation method [10] [11], sol-gel technique [12]-[14], hydrothermal method [15] [16], microwave sintering method [17], spray-spin-heating-coating method [18] and auto combustion method [19]. Out of all these, sol-gel method is promising technique for the synthesis of nano ferrites in bulk scale due to the production of homogeneous particles. The sol-gel method is the most convenient technique to synthesize nanoparticles because of its simplicity, inexpensive precursors, short preparation time, better control over crystallite size and other properties of the materials [20]. The current effort has been focused on studying the composition and frequency-dependent dielectric properties of Cr-Zn ferrites synthesized through sol-gel technique.

\section{Experimental}

\subsection{Synthesis}

Mixed Cr-Zn ferrites having the general formula $\mathrm{Cr}_{x} \mathrm{ZnFe}_{2-x} \mathrm{O}_{4}$ (where $x=0.0,0.1,0.2,0.3,0.4$ and 0.5 ) were prepared using sol-gel method. The detailed structural analysis and magnetic properties of the synthesized $\mathrm{Cr}-\mathrm{Zn}$ nano ferrites samples are reported in our earlier journal [21]. The synthesized powder was pre-sintered at $900^{\circ} \mathrm{C}$ for 3 hrs and cooled slowly to room temperature. The pre-sintered samples were mixed with an organic binder (small quantity of polyvinyl alcohol (PVA)). The mixture was dried and pressed into disk-shaped pellets of 10 $\mathrm{mm}$ diameter and $2 \mathrm{~mm}$ thickness by applying a pressure of 3 tons. The samples were sintered again at $950^{\circ} \mathrm{C}$ for 5 hrs and slowly allowed to cool naturally. For dielectric measurements, silver paint was applied on both sides of the pellets and air dried to have good electrical contact. 


\subsection{Dielectric Measurements}

The dielectric measurements were carried out at room temperature using LCR Meter (Waynekerr Model: 43100) over the frequency range $100 \mathrm{~Hz}$ to $1 \mathrm{MHz}$. The values of capacitance $(C)$ and dissipation factor $(D)$ were noted directly at different frequencies.

The dielectric constant $\left(\varepsilon^{\prime}\right)$ was calculated using the relation [22]

$$
\varepsilon^{\prime}=C t / \varepsilon_{o} A
$$

where $C$ is the capacitance of the sample, $t$ is the thickness; $A$ is the surface area, and $\varepsilon_{o}$ is the permittivity of free space.

From dielectric constant and dissipation factor $(D)$, the ac conductivity $\left(\sigma_{a c}\right)$, of the ferrite samples can be calculated using the relation [23]

$$
\sigma_{a c}=2 \Pi f \varepsilon^{\prime} \varepsilon_{o} D
$$

where $\omega=2 \Pi f$ is the angular frequency.

\section{Results and Discussion}

\subsection{Dielectric Properties}

The dielectric properties of Cr-Zn ferrites have been examined as a function of composition and frequency. Dielectric studies of these samples may be useful for widening its range of applications.

\subsubsection{Frequency Dependence of Dielectric Constant $(\varepsilon$ '}

The frequency dependence of the dielectric constant $(\varepsilon)$ for $\mathrm{Cr}_{x} \mathrm{ZnFe}_{2-x} \mathrm{O}_{4}$ spinel ferrite systems (where $x=0$ 0.5 in steps of 0.1 ) was studied at room temperature in the frequency range of $100 \mathrm{~Hz}$ to $1 \mathrm{MHz}$. Figure 1 displays the variation of dielectric constant $\left(\varepsilon^{\prime}\right)$ as a function of frequency at room temperature. It can be observed that all the samples show strong frequency dependent. The dielectric constant decreases exponentially with increase in frequency, which is very rapid at lower frequencies and slower at higher frequencies. As frequency further, increase dielectric constant become almost independent of frequency. This is a normal dielectric behavior observed in most spinal ferrites [24]-[26]. It can be explained by the Maxwell-Wagner interfacial type

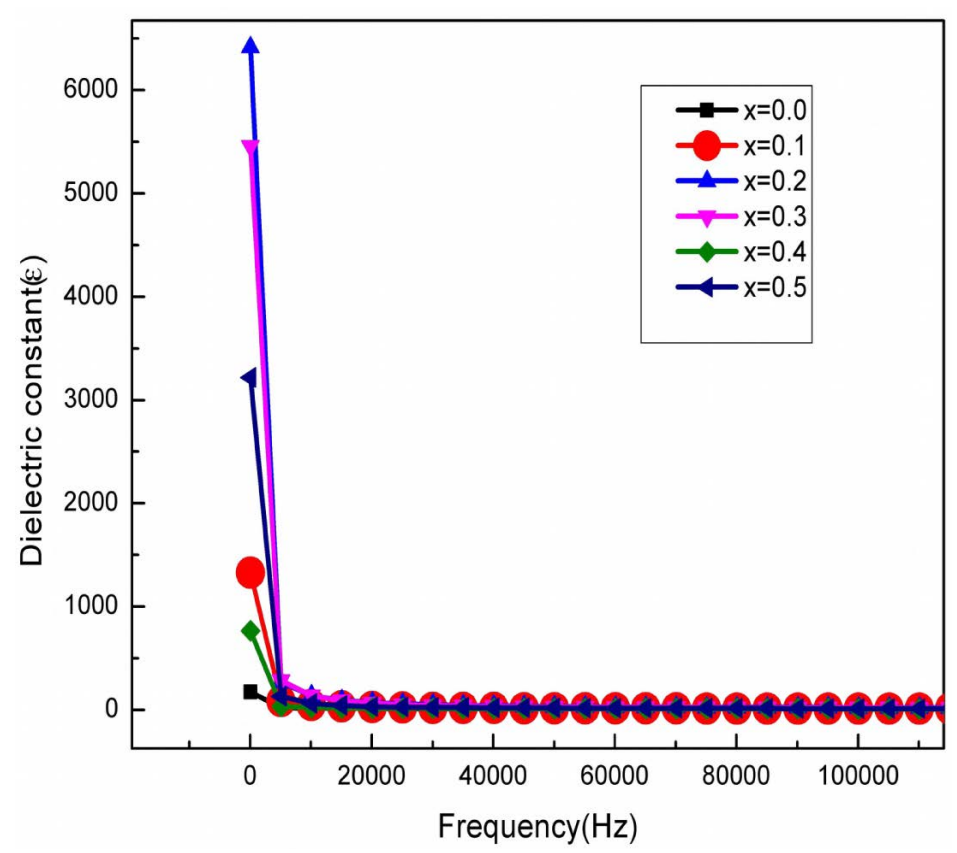

Figure 1. Variation of dielectric constant with frequency for $\mathrm{Cr}_{x} \mathrm{ZnFe}_{2-x} \mathrm{O}_{4}$ $(x=0.0$ to 0.5$)$. 
polarization, which is also in agreement with Koop’s phenomenological theory (Koops, 1951) [27] [28]. According to this model the ferrite composed of good conducting grains separated by poorly conducting grain boundaries. On the application of electric field, the electrons reach the grain boundary through hopping, and if the resistance of the grain boundary is high enough, electrons pile up at the grain boundaries and produce polarization. However, as the frequency of the applied external field is increased beyond a certain value, the hopping frequency cannot follow up the field variation. It decreases the probability of the electrons reaching the grain boundary and as result polarization decreases which in turn causes to the decrement of dielectric constant.

The large value of dielectric permittivity $\left(\varepsilon^{\prime}\right)$ at low frequency is due to the predominance of $\mathrm{Fe}^{2+}$ ions, oxygen vacancies, grain boundary defects, etc., while the decrease in $\varepsilon^{\prime}$ with frequency is due to the lagging of species contributing to polarizability behind the applied electric field. At the higher frequencies $\varepsilon^{\prime}$ remains constant which is attributed to the contribution of electric polarizability only.

\subsubsection{Variation of Dissipation Factor (D) with Frequency}

The variation of dissipation factor $(D)$ against frequency at room temperature is depicted in Figure 2 for $\mathrm{Cr}_{x} \mathrm{ZnFe}_{2-x} \mathrm{O}_{4}$ where $x=0.0$ to $x=0.5$. All the samples exhibit an abnormal behavior of peaking. According to the Iwauchi [29], there is a strong correlation between the conduction mechanism and dielectric behavior of the ferrites. The exchange of electrons between ferrous ions $\left(\mathrm{Fe}^{2+}\right)$ and ferric ions $\left(\mathrm{Fe}^{3+}\right)$ on the octahedral site may lead to local displacement of electrons in the direction of the applied field, and electrons determine the polarization. The dielectric loss in ferrites mainly originates due to the electron hopping and defect dipoles. The electron hopping contributes to the dielectric loss only in the low-frequency range. The response of the electron hopping is decreased with increasing frequency, and hence, the dielectric loss decreases in the high-frequency range. In the meanwhile, dielectric loss peak can be seen in Figure 2 for all the Cr-Zn ferrite samples. The appearance of the relaxation peak can be explained according to Debye relaxation theory [30]. The loss peak can be observed when the applied electric field is in phase with the hopping frequency in dielectric materials. The condition for observing a maximum in dielectric loss of dielectric material is given by

$$
\omega \tau=1
$$

where $\omega=2 \Pi f$, $f$ is the frequency of the applied electric field, and $\tau$ is the relaxation time. The strength and frequency of the relaxation depend on the characteristic property of dipolar relaxation.

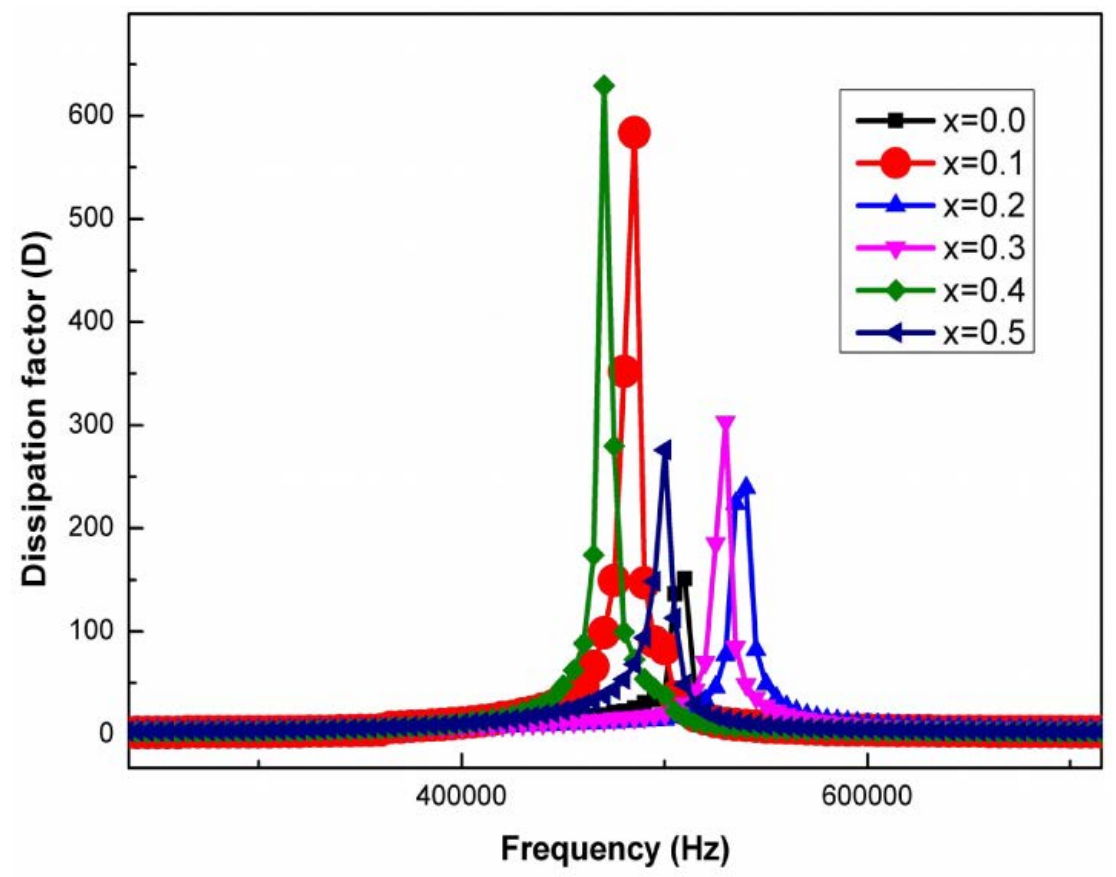

Figure 2. Variation of dielectric factor $(D)$ with frequency for $\mathrm{Cr}_{x} \mathrm{ZnFe}_{2-x} \mathrm{O}_{4}(x=0.0$ to 0.5$)$. 


\subsubsection{Variation of AC Conductivity with Frequency}

Figure 3 shows the ac conductivity of Cr-Zn ferrite system sintered at $950^{\circ} \mathrm{C}$ for $5 \mathrm{hrs}$. Study of ac conductivity of the samples has been performed in the frequency range of $100 \mathrm{~Hz}$ to $1 \mathrm{MHz}$. All the curves exhibit the significant dispersion with frequency, which is an important behavior of ferrites. The electrical conductivity in ferrites is mainly due to the hopping of electrons between the ions of the same element presented in more than one valence state and distributed randomly over crystallography equivalent lattice sites [31]. On the application of ac electrical field, this hopping of electrons gets boosted up, resulting in increasing in ac conductivity. The increase in the frequency of the applied electric field enhances the hopping phenomenon. Hence, there is an increase in ac conductivity.

\subsubsection{Composition Dependence of Dielectric Behavior}

The dielectric constant, dissipation factor and ac conductivity of Cr-Zn ferrite system have measured at a fixed frequency of $1 \mathrm{kHz}$. The values are recorded in Table 1. It is evident from the table that, all the dielectric parameters are greatly affected by Cr-content $(x)$. The dielectric constant increases for all the Cr-substituted Zn-ferrite samples except $\mathrm{Cr}_{x} \mathrm{ZnFe}_{2-\chi} \mathrm{O}_{4}(x=0.4)$ sample. The variation of dielectric constant as a function composition is shown in Figure 4.

Cr-doped Zn-ferrites have higher conductivity than undoped ones. The increase in ac conductivity with the substitution of chromium may be due to the increase in $\mathrm{Fe}^{2+}$ ions at tetrahedral sites, which can increase the hopping of charge carriers between the $\mathrm{Fe}^{2+}$ and $\mathrm{Fe}^{3+}$ ions, and hence, there is an increase in ac conductivity of the Cr-Zn ferrites [32].

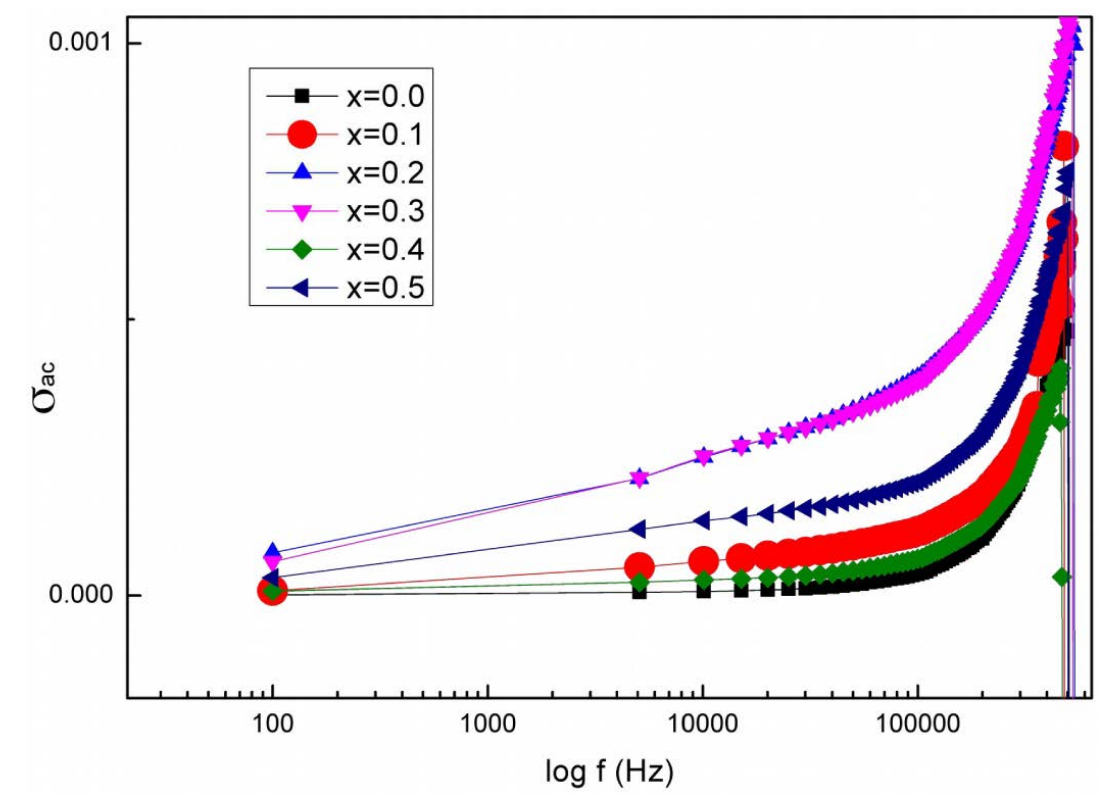

Figure 3. Variation of ac conductivity with frequency for $\mathrm{Cr}_{x} \mathrm{ZnFe}_{2-x} \mathrm{O}_{4}(x=0.0$ to $0.5)$.

Table 1. Dielectric parameters of $\mathrm{Cr}_{x} \mathrm{ZnFe}_{2-x} \mathrm{O}_{4}(x=0.0$ to 0.5$)$ at $1 \mathrm{kHz}$.

\begin{tabular}{ccccc}
\hline S.No & Ferrite composition & Dielectric constant $(\varepsilon)$ & Dissipation factor $(\boldsymbol{D})$ & AC conductivity $\left(\boldsymbol{\sigma}_{\boldsymbol{a c}} \times \mathbf{1 0}^{-6}\right)$ \\
\hline 1 & $\mathrm{Zn} \cdot \mathrm{Fe}_{2} \mathrm{O}_{4}$ & 45.31 & 1.14 & 0.05 \\
2 & $\mathrm{Cr}_{0.1} \mathrm{Zn} \cdot \mathrm{Fe}_{1.9} \mathrm{O}_{4}$ & 330.68 & 1.47 & 0.47 \\
3 & $\mathrm{Cr}_{0.2} \mathrm{Zn} \cdot \mathrm{Fe}_{1.8} \mathrm{O}_{4}$ & 933.49 & 2.45 & 2.23 \\
4 & $\mathrm{Cr}_{0.3} \mathrm{Zn} \cdot \mathrm{Fe}_{1.7} \mathrm{O}_{4}$ & 1144.84 & 1.91 & 2.13 \\
5 & $\mathrm{Cr}_{0.4} \mathrm{Zn} \cdot \mathrm{Fe}_{1.6} \mathrm{O}_{4}$ & 124.12 & 2.35 & 0.28 \\
6 & $\mathrm{Cr}_{0.5} \mathrm{Zn} \cdot \mathrm{Fe}_{1.5} \mathrm{O}_{4}$ & 667.93 & 1.95 & 1.26 \\
\hline
\end{tabular}




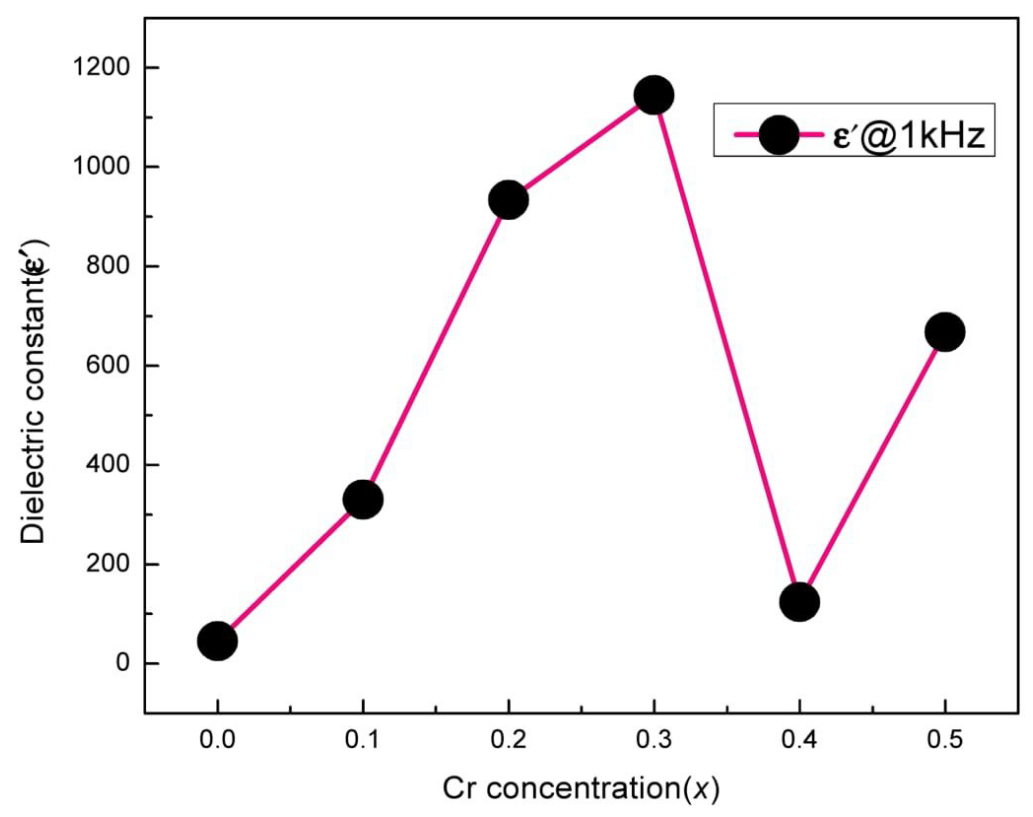

Figure 4. Variation of dielectric constant $\left(\varepsilon^{\prime}\right)$ as function of $\mathrm{Cr}$ content $(x)$ for Cr-Zn nanoferrite samples at $1 \mathrm{kHz}$ frequency.

Figure 2 shows that the height and width of the relaxation peaks have increased unevenly in all the Cr-doped zinc ferrite samples. The increase in peak height with the substitution of $\mathrm{Cr}^{3+}$ ion is due to the increase in conductivity of the sample arising due to the increase of the $\mathrm{Fe}^{3+} / \mathrm{Fe}^{2+}$ ions available for the conduction process. The increase in the peak width is due to the strengthening of the dipole-dipole interactions which hinders the dipole rotation. From Figure 2, it is also important to note that the relaxation peaks of all the Cr-substituted $\mathrm{Zn}$-ferrite samples except $\mathrm{Cr}_{0.2} \mathrm{Zn} \cdot \mathrm{Fe}_{1.8} \mathrm{O}_{4}$ and $\mathrm{Cr}_{0.3} \mathrm{Zn} \cdot \mathrm{Fe}_{1.7} \mathrm{O}_{4}$ samples are shifting towards lower frequency side with an increase in Cr-content. The strength and frequency of the relaxation depend on the characteristic property of dipolar relaxation. From the Table 1, it is clear that the Cr-Zn ferrites possess low dielectric losses. The low dielectric loss makes these samples especially attractive for high-frequency applications.

\section{Conclusion}

Cr doped Zn-ferrites were synthesized by sol-gel method. The dielectric properties have been examined as a function of frequency and composition. The room-temperature dielectric constant decreasing rapidly with increasing frequency indicates the normal dielectric behavior for all the samples. All the substituted samples have higher dielectric constant than the basic Zn-ferrite composition without chromium. Relaxation peaks were observed for all the samples in dissipation versus frequency curves and this relaxation peak is shifting to low frequency side with the substitution of $\mathrm{Cr}$ content $(x)$. The ac conductivity was found to increase with increase in frequency and $\mathrm{Cr}$ concentration. The incorporation of $\mathrm{Cr}^{3+}$ for $\mathrm{Fe}^{3+}$ ions results in a significant impact on the dielectric behavior of the Cr-Zn ferrite system.

\section{References}

[1] Modi, K.B., Gajera, J.D., Chhantbar, M.C., Saija, K.G., Baldha, G.J. and Joshi, H.H. (2003) Structural Properties of Magnesium and Aluminium Co-Substituted Lithium Ferrite. Materials Letters, 57, 4049-4053. http://dx.doi.org/10.1016/S0167-577X(03)00263-5

[2] Ravi Kumar, G., Vijaya Kumar, K. and Venudhar, Y.C. (2012) Synthesis, Structural and Magnetic Properties of Copper Substituted Nickel Ferrites by Sol-Gel Method. Materials Sciences and Applications, 3, 87-91. http://dx.doi.org/10.4236/msa.2012.32013

[3] Ghasemi, A., Ekhlasi, S. and Mousavinia, M. (2014) Effect of Cr and Al Substitution Cations on the Structural and Magnetic Properties of $\mathrm{Ni}_{0.6} \mathrm{Zn}_{0.4} \mathrm{Fe}_{2}-x \mathrm{Cr} x_{/ 2} \mathrm{Al} x_{/ 2} \mathrm{O}_{4}$ Nanoparticles Synthesized Using the Sol-Gel Auto-Combustion Method. Journal of Magnetism and Magnetic Materials, 354, 136-145. http://dx.doi.org/10.1016/j.jmmm.2013.10.022 
[4] Kharabe, R.G., Devan, R.S., Kanamadi, C.M. and Chougule, B.K. (2006) Dielectric Properties of Mixed Li-Ni-Cd Ferrites. Smart Materials and Structures, 15, 36-39. http://dx.doi.org/10.1088/0964-1726/15/2/N02

[5] Nadeem, K., Zeb, F., Azeem Abid, M., Mumtaz, M. and Anis ur Rehman, M. (2014) Effect of Amorphous Silica Matrix on Structural, Magnetic, and Dielectric Properties of Cobalt Ferrite/Silica Nanocomposites. Journal of Non-Crystalline Solids, 400, 45-50. http://dx.doi.org/10.1016/j.jnoncrysol.2014.05.004

[6] Huili, H., Grindi, B., Viau, G. and Tahar, L.B. (2014) Effect of Cobalt Substitution on the Structure, Electrical, and Magnetic Properties of Nanorcrystalline $\mathrm{Ni}_{0.5} \mathrm{Zn}_{0.5} \mathrm{Fe}_{2} \mathrm{O}_{4}$ Prepared by the Polyol Process. Ceramics International, 40, 16235-16244. http://dx.doi.org/10.1016/j.ceramint.2014.07.059

[7] Nadeem, K., Rahman, S. and Mumtaz, M. (2015) Effect of Annealing on Properties of Mg Doped Zn-Ferrite Nanoparticles. Progress in Natural Science: Materials International, 25, 111-116. http://dx.doi.org/10.1016/j.pnsc.2015.02.001

[8] Kripal Sharma, R., Suwalka, O., Lakshmi, N. and Venugopalan, K. (2006) Effect of Particle Size on Hyperfine Fields in Cr-Substituted Nano Co-Zn Ferrite. Synthesis and Reactivity in Inorganic and Metal-Organic and Nano-Metal Chemistry, 36, 175-178. http://dx.doi.org/10.1080/15533170500524546

[9] Xu, Y., Liang, Y.T., Jiang, L.J., Wu, H.R., Zhao, H.Z. and Xue, D.S. (2010) Preparation and Magnetic Properties of $\mathrm{ZnFe}_{2} \mathrm{O}_{4}$ Nanotubes. Journal of Nanomaterials, 2011, 1-5.

[10] Tirupanyam, B.V., Srinivas, Ch., Meena, S.S., Yusuf, S.M., Satish Kumar, A., Sastry, D.L. and Seshubai, V. (2015) Investigation of Structural and Magnetic Properties of Co-Precipitated Mn-Ni Ferrite Nanoparticles in the Presence of $\alpha-\mathrm{Fe}_{2} \mathrm{O}_{3}$ Phase. Journal of Magnetism and Magnetic Materials, 392, 101-106. http://dx.doi.org/10.1016/j.jmmm.2015.05.010

[11] Dey, S., Dey, S.K., Majumder, S., Poddar, A., Dasgupta, P., Banerjee, S. and Kumar, S. (2014) Superparamagnetic Behavior of Nanosized $\mathrm{Co}_{0.2} \mathrm{Zn}_{0.8} \mathrm{Fe}_{2} \mathrm{O}_{4}$ Synthesized by a Flow Rate Controlled Chemical Coprecipitation Method. Physica B: Condensed Matter, 448, 247-252. http://dx.doi.org/10.1016/j.physb.2014.03.073

[12] Pradeep, A., Priyadharsini, P. and Chandrasekaran, G. (2008) Sol-Gel Route of Synthesis of Nanoparticles of $\mathrm{MgFe}_{2} \mathrm{O}_{4}$ and XRD, FTIR and VSM Study. Journal of Magnetism and Magnetic Materials, 320, 2774-2779. http://dx.doi.org/10.1016/j.jmmm.2008.06.012

[13] Hashim, M., Kumar, S., Shirsath, S.E., Kotnala, R.K., Shah, J. and Kumar, R. (2013) Synthesis and Characterizations of $\mathrm{Ni}^{2+}$ Substituted Cobalt Ferrite Nanoparticles. Materials Chemistry and Physics, 139, 364-374. http://dx.doi.org/10.1016/j.matchemphys.2012.09.019

[14] Li, D.-Y., Sun, Y.-K., Xu, Y., Ge, H.-L., Wu, Q. and Yan, C. (2015) Effects of Dy ${ }^{3+}$ Substitution on the Structural and Magnetic Properties of $\mathrm{Ni}_{0.5} \mathrm{Zn}_{0.5} \mathrm{Fe}_{2} \mathrm{O}_{4}$ Nanoparticles Prepared by a Sol-Gel Self-Combustion Method. Ceramics International, 41, 4581-4589. http://dx.doi.org/10.1016/j.ceramint.2014.11.156

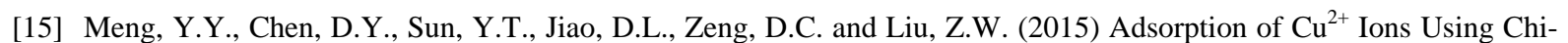
tosan-Modified Magnetic Mn Ferrite Nanoparticles Synthesized by Microwave-Assisted Hydrothermal Method. Applied Surface Science, 324, 745-750. http://dx.doi.org/10.1016/j.apsusc.2014.11.028

[16] Anwar, H., Asghari M. and Gul, I.H. (2015) Effect of Synthesis on Structural and Magnetic Properties of Cobalt Doped Mn-Zn Nano Ferrites. Journal of Alloys and Compounds, 626, 410-414. http://dx.doi.org/10.1016/j.jallcom.2014.11.177

[17] Kumar, P., Juneja, J.K., Prakash, C., Singh, S., Shukla, R.K. and Raina, K.K. (2014) High DC Resistivity in Microwave Sintered $\mathrm{Li}_{0.49} \mathrm{Zn}_{0.02} \mathrm{Mn}_{0.06} \mathrm{Fe}_{2.43} \mathrm{O}_{4}$ Ferrites. Ceramics International, 40, 2501-2504. http://dx.doi.org/10.1016/j.ceramint.2013.07.063

[18] Liu, M., Obi, O., Lou, J., et al. (2009) Strong Magnetoelectric Coupling in Ferrite/Ferroelectric Multiferroic Heterostructures Derived by Low Temperature Spin-Spray Deposition. Journal of Physics D: Applied Physics, 42, 045007. http://dx.doi.org/10.1088/0022-3727/42/4/045007

[19] Roy, P.K. and Bera, J. (2006) Effect of Mg Substitution on Electromagnetic Properties of $\left(\mathrm{Ni}_{0.25} \mathrm{Cu}_{0.20} \mathrm{Zn}_{0.55}\right) \mathrm{Fe}_{2} \mathrm{O}_{4}$ Ferrite Prepared by Auto Combustion Method. Journal of Magnetism and Magnetic Materials, 298, 38-42. http://dx.doi.org/10.1016/j.jmmm.2005.03.007

[20] Srivastava, M., Chaubey, S. and Ojha, A.K. (2009) Investigation on Size Dependent Structural and Magnetic Behavior of Nickel Ferrite Nanoparticles Prepared by Sol-Gel and Hydrothermal Methods. Materials Chemistry and Physics, 118, 174-180. http://dx.doi.org/10.1016/j.matchemphys.2009.07.023

[21] Lakshmi, M., Kumar, K.V. and Thyagarajan, K. (2015) An Investigation of Structural and Magnetic Properties of Cr-Zn Ferrite Nanoparticles Prepared by a Sol-Gel Process Journal of Nanostructure in Chemistry, 5, 365-373. http://dx.doi.org/10.1007/s40097-015-0168-8

[22] Pandya, Rutvi, J., Joshi, U.S. and Caltun, O.F. (2015) Microstructural and Electrical Properties of Barium Strontium Titanate and Nickel Zinc Ferrite Composites. Procedia Materials Science, 10, 168-175. http://dx.doi.org/10.1016/j.mspro.2015.06.038 
[23] Farid, M., Ahmad, I., Aman, S., Kanwal, M., Murtaza, G., Alia, I., Ahmad, I. and Ishfaq, M. (2015) Sem, Ftir and Dielectric Properties of Cobalt Substituted Spinel Ferrites. Journal of Ovonic Research, 11, 1-10.

[24] Ravinder, D. and Kumar, K.V. (2001) Dielectric Behaviour of Erbium Substituted Mn-Zn Ferrites. Bulletin of Materials Science, 24, 505-509. http://dx.doi.org/10.1007/BF02706722

[25] Mohd, H., Shalendra Kumar, A., Shirsath, S.E., Kotnala, R.K., Shah, J. and Kumar, R. (2013) Influence of $\mathrm{Cr}^{3+}$ Ion on $^{2}$ the Structural, ac Conductivity and Magnetic Properties of Nanocrystalline Ni-Mg Ferrite. Ceramics International, 39, 1807-1819. http://dx.doi.org/10.1016/j.ceramint.2012.08.028

[26] Wahbaa, A.M. and Mohamed, M.B. (2014) Structural, Magnetic, and Dielectric Properties of Nanocrystalline Cr-Substituted $\mathrm{Co}_{0.8} \mathrm{Ni}_{0.2} \mathrm{Fe}_{2} \mathrm{O}_{4}$ Ferrite. Ceramics International, 40, 6127-6135. http://dx.doi.org/10.1016/j.ceramint.2013.11.064

[27] Wagner, K.W. (1973) The Distribution of Relaxation Times in Typical Dielectrics. Annals of Physics, 40, 817-819.

[28] Koops, C.G. (1951) On the Dispersion of Resistivity and Dielectric Constant of Some Semiconductors at Audiofrequencies. Physical Review, 83, 121. http://dx.doi.org/10.1103/PhysRev.83.121

[29] Iwachi, K. (1971) Dielectric Properties of Fine Particles of $\mathrm{Fe}_{3} \mathrm{O}_{4}$ and Some Ferrites. Japanese Journal of Applied Physics Part 1, 10, 1520. http://dx.doi.org/10.1143/JJAP.10.1520

[30] Venkataraju, C., Sathishkumar, G. and Sivakumar. K. (2010) Effect of Nickel on the Electrical Properties of Nanostructured MnZn Ferrite. Journal of Alloys and Compounds, 498, 203-206. http://dx.doi.org/10.1016/j.jallcom.2010.03.160

[31] Muddassar, N., Shah, N.A., Gul, I.H. and Maqsood, A. (2009) Structural, Electrical and Magnetic Characterization of Ni-Mg Spinel Ferrites. Journal of Alloys and Compounds, 487, 739-743. http://dx.doi.org/10.1016/j.jallcom.2009.08.057

[32] Sathishkumar, G., Venkataraju, C. and Sivakumar, K. (2013) Magnetic and Dielectric Properties of Cadmium Substituted Nickel Cobalt Nanoferrites. Journal of Materials Science: Materials in Electronics, 24, 1057-1062. http://dx.doi.org/10.1007/s10854-012-0878-3

\section{Submit or recommend next manuscript to SCIRP and we will provide best service for you:}

Accepting pre-submission inquiries through Email, Facebook, Linkedin, Twitter, etc A wide selection of journals (inclusive of 9 subjects, more than 200 journals)

Providing a 24-hour high-quality service

User-friendly online submission system

Fair and swift peer-review system

Efficient typesetting and proofreading procedure

Display of the result of downloads and visits, as well as the number of cited articles

Maximum dissemination of your research work

Submit your manuscript at: http://papersubmission.scirp.org/ 